\title{
Type D personality, lifestyle habits, and cardiovascular disease risk : A mediational model
}

\author{
Almudena Carneiro-Barrera ${ }^{1}$, María Valdés-Díaz ${ }^{2}$ and Juan Francisco Rodríguez-Testal ${ }^{2}$ \\ ${ }^{1}$ Centro de Investigación Mente, Cerebro y Comportamiento, CIMCYC, Universidad de Granada, Granada, España \\ ${ }^{2}$ Universidad de Sevilla, Sevilla, España
}

\begin{abstract}
The interaction of negative affect and stable social inhibition traits (Type D personality) is related to unhealthy lifestyle habits and cardiovascular risk. The aim of this study was to elucidate whether lifestyle habits mediates the relationship between Type D personality and blood pressure (BP) as a cardiovascular risk factor. A total of 91 participants (54.90\% women) aged over 45 years were assessed with measures of subjective health, Type D personality, lifestyle habits and BP. The Baron and Kenny's (1986) model and the Preacher and Hayes' (2008) procedure were used to analyse the mediation model. Results indicated that the relationship between Type D personality and systolic BP was partially mediated by lifestyle habits whereas a full mediation was observed in the case of diastolic BP. The practice of unhealthy lifestyle habits could explain the indirect mechanism by which Type D personality is related to morbidity and mortality risk in cardiovascular patients.
\end{abstract}

Keywords: Type D personality; negative affect; social inhibition; lifestyle habits; cardiovascular risk; mediation.

Personalidad Tipo D, hábitos de vida y riesgo cardiovascular

Resumen: La interacción del afecto negativo e inhibición social (personalidad Tipo D) se relaciona con los hábitos de vida y el riesgo cardiovascular. El objetivo de este estudio fue dilucidar si los hábitos de vida median la relación entre personalidad Tipo D y presión arterial (PA) como factor de riesgo cardiovascular. Un total de 91 participantes mayores de 45 años $(54.90 \%$ mujeres) fueron evaluados de salud subjetiva, hábitos de vida, personalidad Tipo D y PA. Se utilizó el modelo de Baron y Kenny (1986) y el procedimiento de Preacher y Hayes (2008) para el análisis mediacional. Los hábitos de vida mediaron parcialmente la relación entre personalidad Tipo D y PA sistólica y, de manera total, la relación entre personalidad Tipo D y PA diastólica. La práctica de hábitos no saludables podría explicar el mecanismo indirecto mediante el cual la personalidad Tipo D se relaciona con el riesgo de morbilidad y mortalidad en pacientes cardíacos.

Palabras clave: Personalidad Tipo D; afecto negativo; inhibición social; hábitos de vida; riesgo cardiovascular; mediación.

\section{Introduction}

Psychology and medicine have extensively studied the psychological risk factors for Cardiovascular Disease (CVD). Research into the adverse cardiovascular effect of psychosocial factors have proved that depression

Recibido : 07 de junio 2017 ; aceptado : 14 noviembre de 2017 Corresponding author : Juan F. Rodríguez-Testal, Facultad de Psicología, Universidad de Sevilla, C/Camilo José Cela S/N, 41018 Sevilla, Spain. E-mail : testal@us.es

Acknowledgments : We express our gratitude to the professionals and patients of Hospital San Agustín (Sevilla, Spain) for their altruistic contribution in the data collection of this study.
(Barth, Schumacher \& Herrmann-Lingen, 2004), anger and hostility (Chida \& Steptoe, 2009), anxiety (Roest, Martens, de Jonge \& Denollet, 2010), and lack of social support (Barth, Schneider \& von Känel, 2010), are risk components for CVD, both in its onset and its development.

However, what if we consider more stable conditions or personality traits instead of transitory factors? Interest in the association between personality and CVD declined in scientific literature due to conflicting results in studies regarding Type A behavior pattern and CVD (Booth-Kewley \& Friedman, 1987). Nevertheless, recent research suggests new personality variables, which are 
more stable over time and closely related to CVD risk. In this context, the proposal of a personality named Type D arises (Denollet et al., 1996), defined as the union and interaction of two main traits: negative affectivity (NA; propensity to experience negative emotions) and social inhibition (SI; propensity to inhibit emotional and behavioral expression in social contexts).

Considering these distress-traits independently, individuals with NA tend to experience difficulties in coping with daily life events, frequently perceiving environments as stressful and assiduously feeling emotions like tension, worry and dysphoria (Denollet \& Pedersen, 2009). Meanwhile, individuals with high SI are insecure in relationships with others and have a tendency to isolate themselves (Denollet et al., 2006). In this way, SI could be an avoidance of rejections and negative reactions from others to one's own behavior or expression of emotions (Denollet \& Pedersen, 2012).

Denollet (2005) developed a specific test to measure this type of personality: Type D Scale (DS14). The scale includes two 7-item subscales measuring the factors that shape Type D personality: NA ( I often make a fuss about unimportant things») and SI («I often feel inhibited in social interactions»). These items are answered on a 5-point Likert scale, and a standardized cut-off $\geq 10$ on both subscales indicates Type D personality. Highquality psychometric properties of DS14 have been demonstrated internationally by cross-cultural analyses, showing that the Type D measurement is internally consistent and valid across 21 different countries (Kupper et al., 2013).

Evidence gathered about Type D personality related to CVD risk indicates that the conjunction of NA and SI increases the propensity to CVD and mortality risk in cardiac patients: the risk of death from heart disease could be four times higher in people with Type D personality compared with others (Denollet \& Brutsaert, 1998; Denollet, Sys \& Brutsaert, 1995; Denollet, Vaes \& Brutsaert, 2000). Studies also found that Type D personality is associated with major psychological distress, enclosing symptoms of depression, social alienation, anger, anxiety and vital exhaustion (Denollet \& Pedersen, 2009; Montero, Rueda \& Bermúdez, 2012), including worse cognitive performance (Unterrainer et al., 2016), and leading to an adverse health status and medical result (Pluijmers \& Denollet, 2017).

Some authors have considered Type D personality to be solely a measure of NA (Coyne \& de Voogd, 2012). However, it has been proved that it is not simply a mere measurement of affection, it is the inclusion of the way in which people relate to NA and express it within the social field. Thus, the combination of NA and SI has been much stronger than separate predictive factors of death resulting from CVD and repeat heart attacks (Denollet et al., 2006; Pedersen \& Denollet, 2006). According to the authors, the tendency to experience negative emotions with the expression avoidance of these in social interaction is what gives rise to a strong risk factor of CVD (Denollet \& Pedersen, 2012).

Regarding the mechanisms by which Type D personality is associated with CVD, these could be direct and indirect. Focusing on the first, studies which analyzed physiological aspects related to Type D confirmed that subjects with this personality showed increased cardiac output and lower variability of heart rate in comparison to other subjects with other personality types in situations of experimental stress (Williams, O'Carroll \& O'Connor, 2009). NA and SI have also been related to increased blood pressure (BP; Habra, Linden, Anderson \& Weinberg, 2003; Kupper et al., 2013) and elevated levels of cortisol (Molloy, Perkins-Porras, Strike \& Steptoe, 2008) in experimental stress situations.

With regard to the indirect mechanism and alluding to behavioral factors, subjects with such personality showed poor adherence to medical treatment in addition to rigidity in unhealthy lifestyle behaviors (Williams et al., 2008; Williams, Abbott \& Kerr, 2015). Researchers found that Type D personality was related to worse disease perception, lower treatment satisfaction and poor physical and mental health status, which could lead to a poor medication adherence (Mommersteeg, Pot, Aarnoudse, Denollet \& Widdershoven, 2013). In respect to the rigidity in lifestyle behaviors, Type D was associated with an unhealthy diet, poor sleep, infrequent physical exercise, smoking and alcohol consumption (Svansdottir et al., 2013). As scientific literature has exposed, this involves a significant cardiovascular risk since the adherence to medical treatment and the change to a healthier lifestyle habits are key factors for success in the treatment and rehabilitation of CVD (Buceta \& Bueno, 1996; Fernández-Abascal, Martín \& Domínguez, 2003).

Nevertheless, it should be noted that although these physiological and behavioral aspects are the most cited in the study on Type D, their function as mediators between this type of personality and CVD risk has not yet been clarified. Consequently, this study was aimed at achieving a main goal: to verify the possible relationship between Type D personality (as a predictor variable) and systolic/diastolic BP (as a cardiovascular risk) through a mediation model in which healthy lifestyle habits and mental physical health could act as mediator variables. Therefore, the first assumption established was that Type D personality would evidence a significant positive 
relationship with systolic and diastolic BP markers and negative with healthy lifestyle habits and mental and physical health. The second hypothesis was that healthy lifestyle habits and mental and physical health would show a statistically significant negative relationship with systolic and diastolic BP. Finally, the third prediction was that healthy lifestyle habits and mental and physical health would act as mediator variables in the positive relationship between Type D personality and cardiovascular risk (systolic and diastolic BP). Prior to the study of the mediational model, a secondary objective was also pursued: to verify the adequate psychometric properties of the created (HVS) and translated (Type D) instruments used in the data collection. The predictions were that both questionnaires would present suitable values of reliability and validity to be used in the Spanish sample.

\section{Methods}

\section{Participants}

The sample comprised a total of 91 subjects from the Spanish city of Seville (50 women, 54.90) aged between 45 and 84 years $(M=57.63, S D=10.23)$, recruited by the non-probability convenience sampling technique, from among those who attended the general health center Hospital San Agustín (Dos Hermanas, Sevilla) for CVD follow-up visits (32 subjects, $35.2 \%$ ) or any other reason (general medicine or primary care), and met the inclusion criteria. Inclusion criteria were based on being able to understand the tests/questionnaires, being older than 45 years and not presenting any pathology or physical or psychological treatment that could interfere with understanding the tests, and not having any kind of addiction to alcohol or other drugs (all collected on specific issues in the First Self-reported Evaluation).

The educational level of the participants ranged from a low (primary school) to a high level of education (university, specialization, etc.), being predominantly medium or basic level. None of them displayed any reading comprehension problem, physical disability (auditory, visual or motor) or mental disorder.

\section{Procedure}

Data collection was performed by a cross-sectional design and with a self-reported pencil and paper format. A dossier with all the self-report instruments was given to each participant by one of the psychologists in charge of this research, and explanations were only to clarify any questions or problems with the assessment format.
Data was collected between January and April 2016 from the general health center attended by the participants, Hospital San Agustín (Dos Hermanas, Sevilla). All participants were informed about the voluntariness, confidentiality of data and the purposes pursued in this study, and signed informed consent to participate in the investigation.

\section{Instruments}

First self-reported evaluation. An initial questionnaire was designed to collect the following general information: social-demographic data, history of diseases, medical and psychological treatments, and consumption of alcohol or any other drugs.

General Health Questionnaire (GHQ-28; Goldberg, 1979). The Spanish version of this questionnaire was used (Lobo, Pérez-Echeverría \& Artal, 1986). This screening test consists of four 7-item subscales (somatization, anxiety, social dysfunction and depression), with a total of 28 items. The subjects answered on a 4-point Likert scale indicating if they had presented the symptom and whether or not they were better than usual. The Spanish version of the questionnaire showed good internal consistency (Cronbach's $\alpha$ coefficients were .97 for the whole scale, .93 for somatization, .92 for anxiety, .91 social dysfunction, and .97 for depression). In this study, the reliability of this scale was Cronbach's $\alpha=.95$ for the whole scale and $\alpha=.92, \alpha=.92, \alpha=.83, \alpha=.77$ for somatization, anxiety, social dysfunction and depression subscales, respectively.

Short Form 12 Health Survey (SF-12; Ware, Kosinski \& Keller, 1996). The Spanish version of the questionnaire was used (Gandek et al., 1998) The SF12 is a shortened version of the SF-36 and consists of a selection of 12 items on mental and physical health issues, which subjects must respond to on a Likerttype scale. A higher score signifies better health. The scale provides two summary components: physical health (physical functioning, physical role, bodily pain and general health) and mental health (vitality, social function, emotional role and mental health). The Spanish validation showed good reliability, (Cronbach's $\alpha$ from .68 to .94). Internal consistency of this instrument in the current sample was Cronbach's $\alpha=.89$ for both components, physical and mental health.

Type D Scale (DS14; Denollet, 2005). Due to the fact that this study began prior to the Spanish validation of this scale performed by Montero, Bermúdez and Rueda (2017), the original version was translated into Spanish (Rodríguez-Testal, 2017). Translation and adaptation of instruments guidelines were followed (Sousa \& 
Rojjanasrirat, 2013), and the parallel back-translation procedure was used to ensure the linguistic validation of the Spanish version of the DS14. This scale consists of two 7-item subscales (NA and SI). The subjects responded on a 4-point Likert-type scale, scoring from 0 (false) to 4 (true), exposing their agreement or disagreement with the descriptions of the items. A standardized cutoff $\geq 10$ in both subscales indicates Type D personality. The reliability of the original scale by Denollet (2005) was Cronbach's $\alpha=.88$ and $\alpha=.86$ for the subscales of NA and SI, respectively. The Spanish adaptation and validation of this scale (Montero, Bermúdez \& Rueda, 2017), also showed good internal consistency (between .85 y .90$)$.

Healthy Lifestyle Habits (HVS). Experimental questionnaire by Carneiro-Barrera and Rodríguez-Testal (2017). This instrument is composed of 10 behavioral habit questions concerning sedentary lifestyle, sleep, diet, consumption of alcohol, coffee, smoking and exercise. In addition, it collects weight and height measurements (to calculate body-mass index, BMI), and systolic and diastolic BP. The answers vary from hours per day or week (How many hours do you sleep daily?) to portions or units per day or week (How many units of fruit do you eat per day?). The raw scores were evaluated and recoded to $0,1,2$ and 3, indicating low to high healthy habit (see Appendix), taking into account the following: (1) Question 1 (hours of watching TV) was ranked with a maximum of two hours a day considering a study published in the Journal of the American Medical Association (JAMA; Grøntved \& Hu, 2011); (2) for question 2 (hours of sleep), the National Sleep Foundation (Hirshkowitz et al., 2015) recommendations of 8 hours per day were taken into account; (3) questions 3,4 and 5 (consumption of fruits, vegetables, and carbohydrates, respectively) were ranked considering the Sociedad Española de Dietética y Ciencias de la Alimentación (SEDCA, 2011) recommendations of 400 $\mathrm{g}$ daily of fruit and vegetables (3 units of fruit per day and 2-3 portions of vegetables per day) and 4 portions of carbohydrates per day; (4) in questions 6, 7, 8 and 9 (consumption of coffee / tea, tobacco and alcohol, respectively), 0 units per day/week was established as healthy, and they were sorted by frequency analysis of the sample; (5) for question 10 (physical activity) the reference of 150 minutes per week was taken as the World Health Organization (WHO, 2004) recommendation indicates; (6) BMI was classified according to the WHO Expert Consultation (2004) classification; and finally, (7), systolic and diastolic BP were classified according to quartiles of the sample determined by frequency analysis.
Blood pressure and body-mass index. A portable upper arm BP monitor and a sliding weight column scale were used as appliances to measure participants systolic and diastolic BP and calculation of BMI.

\section{Data analyses}

Firstly, descriptive and frequency statistical analyses of variables such as age and sex were performed. All variables used in the study (scales and subscales) were transformed to $\mathrm{Z}$ scores to reduce possible multicollinearity, and subjected to reliability analysis using Cronbach's $\alpha$ statistic.

Secondly, in order to verify the adequate psychometric properties of the created (HVS) and translated (Type D) instruments used in the data collection, internal consistency analyses of these scales were performed using Cronbach's $\alpha$ statistic. Regarding the validity of these same scales, Pearson's correlation coefficients of the Type D scale and GHQ-28 factors were calculated to verify convergent validity of the translated Type D scale. With respect to the created HVS and Type D scale, properties of the scales and construct validity were analyzed by an exploratory factorial analysis (Robust Maximum Likelihood method) Direct Oblimin rotation, the number of factors was decided considering parallel analysis.

Finally, with regard to the core objective, Pearson's correlation coefficients for all variables included in the mediation model were calculated, i.e. Type D scale, systolic and diastolic BP, HVS and mental and physical health factors (SF-M, SF-P) of SF-12. Subsequently, a mediation analysis was conducted which approximates the association and magnitude of potential causal variables of a phenomenon (Hayes \& Preacher, 2014). This begins with a possible cause-effect relationship between an independent variable $X$ (Type D) and a dependent variable $Y$ (systolic and diastolic BP). The objective is to identify the role of other variables, $M$ (HVS, SF-M and SF-P) involved as mediators of the relationship between $X$ and $Y$, controlling any covariate (age). For this reason, Baron and Kenny (1986) model based on a significant relationship between the independent variable (Type D) and dependent (systolic and diastolic BP) was used. The total effect of this relationship (significant coefficient $C$ ), significant relationships needed between the mediating variables (HVS, SF-M and SF-P) and the independent variable (significant $a$ effect) as well as with the dependent variables (significant $b$ effect) were estimated. For the mediation model to be valid, the relationship between the independent and dependent variable should be 
influenced by the inclusion of the mediator variable to the point of losing significance (full mediation, $C^{\prime}=0$ ) or reducing it (partial mediation, $\left.C^{\prime} \neq 0\right)\left(C^{\prime}\right.$ less than the indirect effect $a \bullet b$ ) (García \& Vallejo, 2011).

A multiple mediation analysis was performed using the Preacher and Hayes (2008) resampling procedure (Montecarlo), using a confidence interval of $95 \%$ and 5,000 iterations to calculate the coefficient of the indirect effect. This is a powerful procedure that surpasses the limits of others at calculating $a$ • $b$, not assuming that $a$ and $b$ are not correlated and identifying effects even in small samples that do not follow a normal distribution. The MEDIATE macro for the SPSS program version 22 was used to estimate the significance of the mediator variables and control any influences of covariates (http://www.afhayes.com/ public/mediate.sps). All analyses were accepted with a significance of $p<.05$.

\section{Results}

\section{Preliminary reliability analysis of the scales and} subscales used

Reliability analysis of all scales and subscales were estimated. All scales and subscales showed high reliability by Cronbach's alpha statistic, as shown in Table 1 and described in the instruments section. It should be noted that Type D scale presented good internal consistency, whereas HVS showed acceptable indicators of reliability.

Table 1. Internal consistency of Type D scale and HVS $(n=91)$

\begin{tabular}{lc}
\hline & Cronbach's $\alpha$ \\
\hline Type D & .94 \\
Type D-NA & .89 \\
Type D- SI & .91 \\
HVS & .68 \\
\hline
\end{tabular}

Convergent and construct validity analysis of the Type D scale

Regarding the convergent validity, Table 2 shows the performed bivariate Pearson's correlation analysis between Type D and GHQ-28 scales (subscales A, B, C and D). Type D scale showed highly significant positive correlations with the subscales A (somatization), B (anxiety), C (social dysfunction) and D (depression) of the GHQ-28.

A factorial analysis was performed to analyse the contruct validity of the scale, using the maximumlikelihood estimation procedure and Varimax rotation (eigenvalues $>1$ ). Only those items greater than or equal to .30 saturation were selected. The KMO index was .86 and the Barlett's sphericity test was significant $(p<$ .0001 ). The result suggested two factors: NA (items 13, 12, 7, 9, 2, 4 and 5), and SI (items 8, 1, 14, 6, 11, 10, and 3 ), explaining a $37 \%$ of the variance.

\section{Construct validity analysis of the HVS questionnaire}

In respect to construct validity, an exploratory factorial analysis (Robust Maximum Likelihood method) with Direct Oblimin rotation was performed. Parallel analysis recommended a two-factor solution. Previously, KMO index and Bartlett's sphericity test were used to verify that the original variables can be factorized efficiently to ensure that the correlation matrix is appropriate, obtaining adequate results (KMO's test $=.74$; Barlett's test $=p<.05$ ). As shown in Table 3, the questionnaire demonstrated construct validity as it was structured on two factors that explained $51 \%$ of variance: factor I «rest-exercise» (sport, sleep and hours of watching TV); and factor II «eating-consumption» (coffee, alcohol-spirit, smoking, fruit and vegetables).

Table 2. Bivariate correlations between Type D total scale and subscales and GHQ subscales $(n=91)$

\begin{tabular}{|c|c|c|c|c|c|}
\hline & $M$ & $S D$ & 1 & 2 & 3 \\
\hline 1. Type D & 23.62 & 11.23 & - & & \\
\hline 2. Type D-NA & 12.73 & 5.55 & $.913 * *$ & - & \\
\hline 3. Type D-SI & 10.89 & 6.56 & $.939 * *$ & $.717 * *$ & - \\
\hline 4.GHQ-A & 5.90 & 4.28 & $.781 * *$ & $.729 * *$ & $.719 * *$ \\
\hline 5.GHQ-B & 5.69 & 4.69 & $.793 * *$ & $.802 * *$ & $.679 * *$ \\
\hline 6.GHQ-C & 8.25 & 2.37 & $.667 * *$ & $.676^{* *}$ & $.570 * *$ \\
\hline 7.GHQ-D & 1.33 & 2.17 & $.624 * *$ & $.623 * *$ & $.541 * *$ \\
\hline
\end{tabular}

Note: Type D-NA: Negative Affect; Type D-SI: Social Inhibition; GHQ: Goldberg General Health Questionnaire; GHQ-A: Somatization; GHQ-B: Anxiety; GHQ-C: Social Dysfunction; GHQ-D: Depression. ** $p<.01$ 
Table 3. Factorial structure and internal consistency of HVS scale $(n=91)$

\begin{tabular}{lcc}
\hline \multicolumn{1}{c}{ HVS scale items } & Factor I & Factor II \\
\hline 2. How many hours do you sleep per day? & .717 \\
10. How many hours do you dedicate to exercise per week? & .674 \\
1. How many hours do you dedicate to watch television per day? & .613 & .354 \\
4. How many portions of vegetables do you consume per day? & -.308 \\
5. How many portions of carbohydrates do you consume per day? & .368 \\
9. How many alcoholic units of spirit do you drink per week? & .843 \\
7. How many cigarettes do you smoke per day? & .619 \\
3. How many pieces of fruit do you consume per day? & .547 \\
8. How many alcoholic units of beer do you consume per week? & .457 \\
6. How many cups of tea or coffee do you drink per day? & .396 \\
Explained variance & 3.49 \\
Eigenvalues & .66 \\
Internal consistency Cronbach's $\alpha$ & $.63 \%$ \\
\hline
\end{tabular}

Note: HVS: Healthy lifestyle habits

Table 4. Bivariate Pearson's correlations of the different scales included in the mediation model $(n=91)$

\begin{tabular}{|c|c|c|c|c|c|c|c|c|c|}
\hline & $M$ & $S D$ & 1 & 2 & 3 & 4 & 5 & 6 & 7 \\
\hline 1. Age & 57.63 & 10.23 & 一 & & & & & & \\
\hline 2.Type D & 23.62 & 11.23 & $.336 * *$ & - & & & & & \\
\hline 3. HVS & 19.08 & 4.88 & -.140 & $-.620 * *$ & - & & & & \\
\hline 4. SF-M & 10.67 & 3.23 & $-.339 * *$ & $-.868 * *$ & $.604 * *$ & - & & & \\
\hline 5. SF-P & 13.44 & 4.56 & $-.502 * *$ & $-.650 * *$ & $.481 * *$ & $.673 * *$ & - & & \\
\hline 6. BP systolic & 13.12 & 1.53 & $.419 * *$ & $.591 * *$ & $-.519 * *$ & $-.542 * *$ & $-.447 * *$ & - & \\
\hline 7. BP diastolic & 8.45 & 1.20 & $.306 * *$ & $.507 * *$ & $-.581 * *$ & $-.492 * *$ & $-.499 * *$ & $.738 * *$ & - \\
\hline
\end{tabular}

Note: HVS: Healthy lifestyle habits; SF-M: Mental Health; SF-P: Physic Health; BP: Blood Pressure. ${ }^{* *} p<.01$

\section{Mediation model analysis}

As a preliminary step to the mediation analysis, a bivariate correlation analysis between all variables in the mediation model was performed (Type D, systolic BP, diastolic BP, HVS, SF-P, SF-M and age as possible covariate). As showed in Table 4, statistically significant relationships of the Type D scale with systolic and diastolic BP variables as well as with possible mediator variables (HVS, SF-M and SF-P) were found. These mediator variables were also related to systolic and diastolic BP (dependent variables). These relationships were prerequisites to continue the mediation analysis. The possible effect of age as a covariance was confirmed, showing significant relationships with the independent (Type D) and dependent (systolic and diastolic BP) variables.

Once all the prerequisites were verified, multiple mediation analyses were performed in order to confirm the mediator role of HVS, SF-P and SF-M, on the relationship between Type D and systolic and diastolic BP. The age was taken as a covariate. Figure 1 shows the general mediation model where statistically significant relationships between independent, mediator and dependent variables, as well as the effect of the covariance (age), are represented.

As shown in Table 5, the total effect $(C)$ of the relationships between the independent variable Type $D$ and dependent variables systolic and diastolic BP were statistically significant, $F(2,88)=29.89, p<.01$ and $F$ $(2,88)=16.93, p<.01$, respectively, explaining $39.10 \%$ of the variance in the case of the systolic, and $26.14 \%$ in the diastolic. The non-standardized coefficient $\beta$ of Type D was $2.88(t=5.81 ; p<.01)$ for systolic and $2.54(t=4.74 ; p<.01)$ for diastolic. The omnibus test, considering age as a covariate, was also significant $(F=$ 22.48, $p<.01)$.

Relationships between the independent variable (Type D) and mediator variables (HVS, SF-P and SFM) were also statistically significant. A $37.60 \%$ of the variance was explained for HVS, $50.22 \%$ for SF-P and $75.06 \%$ for SF-M. The relationship between HVS and Type D was significant $(t=-7.31, p<.01)$ and age as a covariate was not significant $(p>.05)$. The relationship between SF-P and Type D was also significant $(t=-6.88$, $p<.01)$ and age as covariate was significant $(p<.01)$. 
Finally, the relation between SF-M and Type D was also significant $(t=-15.21, p<.01)$ and age as covariate was not significant in this case $(p>.05)$.

Relationships between mediators and dependent variables (systolic and diastolic BP) were only significant in the case of HVS with systolic BP (non-standardized coefficient $\beta=-.07, p<.01)$ and diastolic $\mathrm{BP}(\beta=-.09, p$ $<.001$ ), so the variables SF-P and SF-M disappeared as mediators in the model.

The models including systolic BP and diastolic BP explained $42.19 \%$ and $38.26 \%$ of the variance, respectively, so there was an improvement in the percentage of variance explained by the inclusion of mediator variables (HVS) and covariance. In the omnibus test, the direct effect $\left(C^{\prime}\right)$ of the Type D independent variable in the systolic and diastolic BP dependent variables, including HVS as a mediator variable, was significant in the case of systolic BP $(F=4.28, p<.05)$ and not significant in the case of diastolic BP $(F=.28$, $p>.05)$. Therefore, there was a decrease of the direct effect on the non-standardized coefficient $\beta$ to 1.98 in the case of systolic BP (the total effect was before 2.88) and .51 in diastolic BP (the total effect was before 2.54). This corroborated a partial mediation regarding systolic BP (although the effect remained significant, it strongly decreased) and, in the case of the diastolic BP, a total mediation as the total effect disappeared completely by introducing the mediator variable.

In summary, according to the model proposed by Baron and Kenny (1986), there would be mediation as noted: first, that the independent variable Type D influenced dependent variables systolic BP (total effect $C=2.88, p<.01$ ) and diastolic BP (total effect $C=$ $2.54, p<.01)$; secondly, that the variable Type $\mathrm{D}$ was significantly related to the mediating variables HVS, SF-M and SF-P $(p<.01)$; thirdly, that only the mediator HVS was significantly related to the dependent variables systolic and diastolic BP; and finally, the predictor effect of Type D to systolic BP decreased by including the mediator HVS (effect direct $C^{\prime}=1.98, p<.05$ ) and completely disappeared for diastolic BP (direct effect $\left.C^{\prime}=.51, p>.05\right)$, suggesting that a partial and a full mediation was reached.

The homogeneity test of the interaction regression $(X \bullet M)$ showed that the variance in the scores of these variables were adequate for the mediator variable (HVS), as well as for the omnibus test $(F=1.19, p>.05)$. The indirect effect $a \times b$ of the independent variable Type D in mediator variable HVS was significant (see confidence intervals in Table 5).

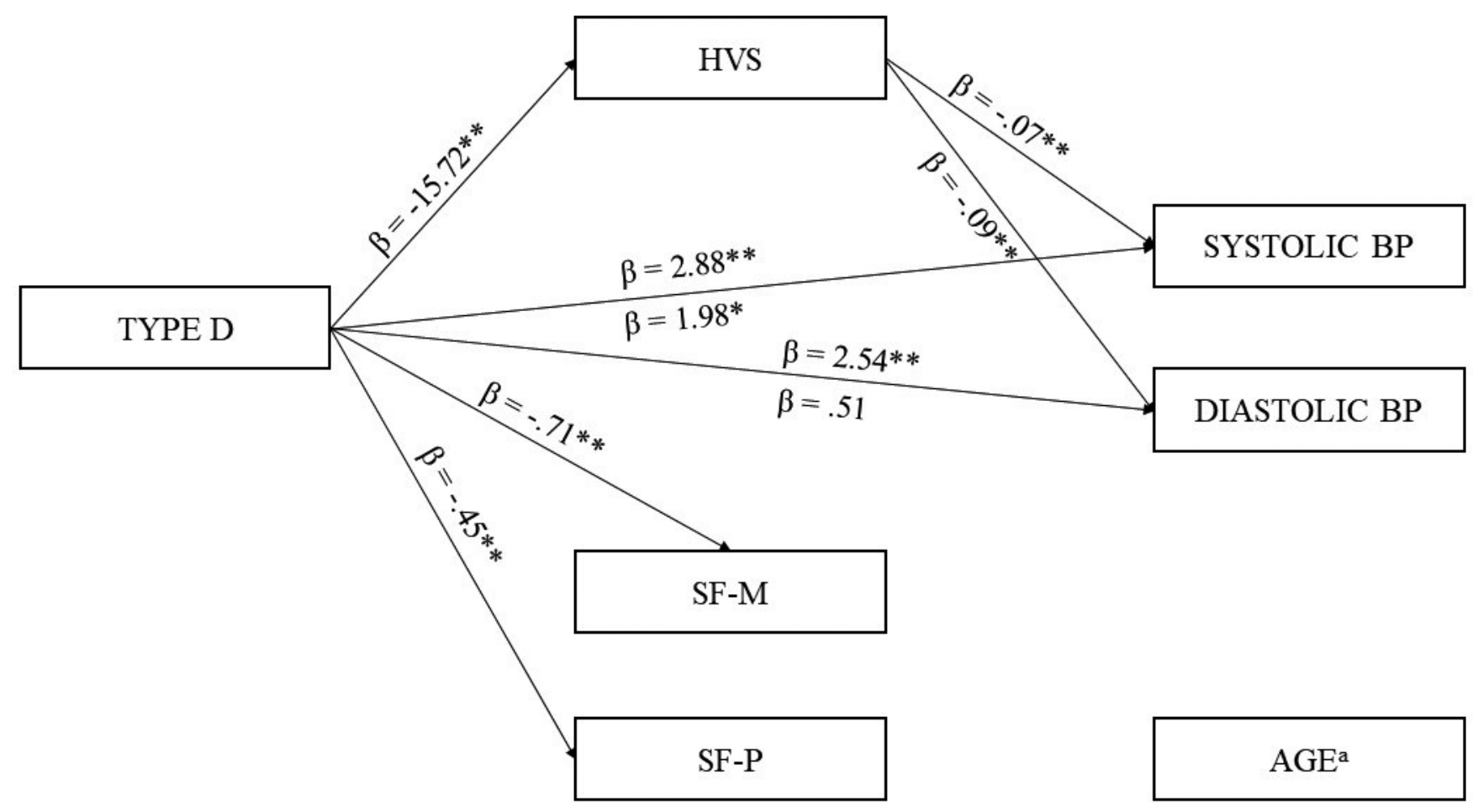

Note: $\beta=$ non-standardized coefficient; HVS: Healthy lifestyle habits; SF-M: Short Form-Mental health; SF-P: Short Form-Physical Health; BP: Blood Pressure. ${ }^{a}$ Age as a significant covariance only in the SF-P and Type D relation $* p<.05 ; * * p<.01$

Figure 1. Multiple mediation model with Type D as predictor of systolic and diastolic BP 
Table 5. Mediation analysis of mediators HVS, SF-M and SF-P in the relation between Type D and systolic and diastolic BP

\begin{tabular}{|c|c|c|c|c|c|c|c|c|}
\hline \multirow[t]{2}{*}{$\begin{array}{l}\text { Independent } \\
\text { variables }(X)\end{array}$} & \multirow[t]{2}{*}{$\begin{array}{c}\text { Mediator } \\
\text { variables }(M)\end{array}$} & \multirow[t]{2}{*}{$\begin{array}{c}\text { Dependent } \\
\text { variables }(Y)\end{array}$} & \multirow[t]{2}{*}{$\begin{array}{l}\text { Effect of } X \\
\text { on } M(a)\end{array}$} & \multirow[t]{2}{*}{$\begin{array}{c}\text { Efect of } M \text { on } Y \\
\text { controlled by } X(b)\end{array}$} & \multirow[t]{2}{*}{$\begin{array}{c}\text { Total } \\
\text { Effect } C\end{array}$} & \multirow[t]{2}{*}{$\begin{array}{c}\text { Direct } \\
\text { Effect } C\end{array}$} & \multicolumn{2}{|c|}{$\begin{array}{l}\text { Indirect Effect } \\
\text { Montecarlo }\end{array}$} \\
\hline & & & & & & & $a \times b$ & $95 \% C I$ \\
\hline Type D & HVS & $\begin{array}{l}\text { Systolic BP } \\
\text { Diastolic BP }\end{array}$ & $-15.72 * *$ & $\begin{array}{l}-.07 * * \\
-.09 * *\end{array}$ & $\begin{array}{l}2.88 * * \\
2.54 * *\end{array}$ & $\begin{array}{c}1.98^{*} \\
.51\end{array}$ & $\begin{array}{l}1.05 \\
1.53\end{array}$ & $\begin{array}{l}.26-1.91 \\
.72-2.45\end{array}$ \\
\hline Type D & SF-M & $\begin{array}{c}\text { Systolic BP } \\
\text { Diastolic BP }\end{array}$ & $-.71 * *$ & $\begin{array}{l}-.13 \\
.04\end{array}$ & & & & \\
\hline \multirow[t]{2}{*}{ Type D } & SF-P & $\begin{array}{l}\text { Systolic BP } \\
\text { Diastolic BP }\end{array}$ & $-.45 * *$ & $\begin{array}{c}.54 \\
-1.17\end{array}$ & & & & \\
\hline & & & Covariance & AGE & $\begin{array}{c}.03^{* *} \\
\text { (systolic) } \\
.01 \\
\text { (diastolic) }\end{array}$ & $\begin{array}{c}.03 * * \\
\text { (systolic) } \\
.01 \\
\text { (diastolic) }\end{array}$ & & \\
\hline
\end{tabular}

Note: The data shows the non-standardized coefficient $\beta$ and are based on Montecarlo for 5,000 iterations. CI: confidence interval (a confidence interval that does not contain zero indicates a significant mediation of the mediator and the independent variable controlling all other mediators). HVS: Healthy lifestyle habits. SF-M: Mental Health. SF-P: Physical Health. BP: Blood Pressure. * $p<.05 ; * * p<.01$

\section{Discussion}

Based on the pioneering studies of Denollet et al. (1996) into Type D personality and cardiovascular risk, this study followed the main objective of verifying how the interaction of NA and SI stable traits is related to CVD risk, studying the possible causal relation through the inclusion of potential mediator variables such as HVS and mental and physical health.

As a prerequisite to study the Type D and CVD risk relationhip, psychometric aspects of the Spanish version of the Type D scale were analysed to confirm it measures both NA and SI related traits as scientific literature exposes. As predicted, results showed how the Spanish version of the DS14 scale meets the requirements of reliability and validity necessary to consider it as a potential measuring technique for Type $\mathrm{D}$ personality, as Denollet (2005) designed it. The reliability of the scale was high, as well as components NA and SI separately. Also, convergent validity was confirmed, showing significant and positive relationships between the Type D scale and somatization, anxiety, social dysfunction and depression factors of the GHQ-28 scale. This further confirms the equivalence exposed on crosscultural studies of Type D measurement in 21 countries (Kupper et al., 2013) and supports previous research that indicated this type of personality is associated with greater psychological distress, involving symptoms of depression, social alienation, anxiety and vital exhaustion (Denollet \& Pedersen, 2009; Montero, Rueda \& Bermúdez, 2012; Pluijmers \& Denollet, 2017).

Another step prior to checking the relationship between Type D and cardiovascular risk was to demonstrate the psychometric properties of the healthy lifestyle habits scale (HVS), created for this study in order to analyze the mediation model. As it was established in the predictions, the HVS scale showed acceptable internal consistency and construct validity, being composed of two main factors (rest-exercise and eating-consumption) which explained a high percentage of the variance.

The main objective of the study was to verify the mediation model of the Type D personality influence on cardiovascular risk mediated by lifestyle habits and mental and physical health, as an indirect mechanism of occurrence of this phenomenon.

Firstly, the results showed a significant positive relation of Type D with systolic and diastolic BP and negative with HVS, SF-M and SF-P, as predicted in the first hypothesis. Although without direction in the relationship, this means that a higher score in stable traits NA and SI is related to higher levels of systolic and diastolic BP and less practice of healthy lifestyle habits, mental health and physical health. This corroborates what previous studies established about this type of personality being related to poor adherence to medical treatment (Denollet \& Pedersen, 2012), and rigidity in unhealthy lifestyle behaviors (Svansdottir et al., 2013; Williams et al., 2008; Williams et al., 2015).

Secondly, based on the correlation analysis, only HVS was related to cardiovascular risk, removing mental and physical health as potential mediators, and partially affirming the second prediction. This supports the consideration of habits such as smoking, poor diet and physical inactivity as potential risk factors of CVD (Buceta \& Bueno, 1996; Fernández-Abascal et al., 
2003). This was important since it assumed that the intervening variables in the mediation model Type D, systolic and diastolic BP and HVS had significant and solid correlations.

Once all the previous hypotheses were confirmed, specific analyses of the HVS variable as a mediating factor between the effects of Type D on cardiovascular risk were performed. The results partially confirmed the third and final assumption, asserting that there was a mediated relationship between Type D and systolic and diastolic BP by HVS.

On one hand, HVS acted as a possible mediator in the relationship between Type D and systolic BP as there was a moderate decrease in the direct effect coefficient of these variables, in respect to the total effect, after introducing the mediator HVS and controlling age as a covariate. This means a partial mediation was found since the relationship between Type D and CVD risk did not disappear (as full mediation requires), and the model explained a high percentage of the variance. On the other hand, the variable HVS was confirmed as a mediator factor between Type D and diastolic BP, producing a full mediation since the significance of the direct effect coefficient completely disappeared compared to the total effect. This means that when introducing HVS, the influence of Type D in cardiovascular risk only occurs by considering HVS. This model also explained a high percentage of the variance.

The higher level of mediation in diastolic BP in comparison to systolic BP could be explained referring to studies which exposed that a cognitive type of coping to repress emotions such as anger, and the perception of most daily stressors as more stressful, were related to increased heart rate and diastolic BP but not systolic BP (Bongard \& Hodapp, 1997; Cea, González \& Brazal, 2002; Coy, 1998; Molerio \& García, 2004).

In summary, results in this study showed that unhealthy lifestyle habits such as smoking, poor diet and sleep, less practice of exercise and alcohol consumption mediate the adverse cardiovascular effect of Type D personality, possibly being the indirect mechanism by which the conjunction of NA and SI traits is associated with high CVD risk. This supports previous findings which also confirmed that the relationship between Type $\mathrm{D}$ and CVD arises from unhealthier behaviors, suggesting that Type D individuals were current smokers, did less exercise and had a higher BMI (Svansdottir et al., 2013).

In depth, people with high NA and SI tend to perceive the environment as stressful in their daily life, displaying coping styles focused on emotions of worry, tension and dysphoria (Denollet \& Pedersen, 2009), and avoiding the expression of them in social contexts as a form of preventing rejection or negative evaluation by others (Denollet et al., 2006). Thus, these people would appear to be withdrawn, inarticulate, timid and excessively worried when attending medical consultations, in addition to perceiving professionals with more hostility than other patients (Denollet \& Pedersen, 2012). Consequently, low medical adherence combined with unhealthy practices like drinking coffee, smoking, alcohol abuse and physical inactivity (all related to NA and SI) would lead to a worse diagnosis, prognosis and treatment of CVD in these patients.

This study provides very interesting and innovative results, but it should be recognized that although the mediation analysis enables an approach to causal relationships (Hayes \& Preacher, 2014), these are merely attempts. Psychometric properties of the created and used scales (HVS and Type D) should be improved, as well as aspects of design and data collection. The crosssectional design limits the comparison of the process and development of heart disease in patients with Type D personality and others. Additionally, another design disadvantage was that the cardiovascular risk was considered by markers in BP, resulting in major limitations in establishing cause-effect phenomena with certainty. To address these constraints, increasing the sample size, measuring BP several times to decrease the reactivity to the measurement, and longitudinal measures in cardiac patients, as well as considering control groups, could optimize the study and interpretation of the results, allowing the establishment of independent, mediator and dependent variables in the most accurate way.

In conclusion, this study supports the need for and importance of the use of psychological management focusing on distress, social alienation and lifestyle habits in the prevention and treatment of CVD, not only in elderly cardiac patients but especially in young people to whom Type $\mathrm{D}$ is potentially a stronger risk in cardiac morbidity and mortality (Denollet, Tekle, Van der Voort, Alings \& Van den Broek, 2013). Unhealthy habits, NA and SI, as modifiable risk factors and consequences of CVD, should be treated in primary care and prevention as well as in cardiac rehabilitation programmes. Future research should focus on all of these relations since there are not many studies relating Type D personality to BP and perceived health status. The inclusion of other possible mediator variables such as weight or BMI could also yield relevant results, as well as analyzing the role of the variable sex within more complex mediation models. Similarly, future investigations should expand the study of the consequences of Type D personality, as the adverse health outcomes related to this type of personality have also been recently related to other diseases and chronic 
illnesses such as cancer, type 2 diabetes, osteoarthritis or rheumatoid arthritis and fibromyalgia (Horwood, Anglim \& Tooley, 2016). The establishment of new lines in this direction would definitely assist improvements in routine clinical practice and within the health system.

\section{Conflicts of interest}

Authors declare there are no conflicts of interest.

\section{References}

Baron, R. M., \& Kenny, D. A. (1986). The moderator-mediator variable distinction in social psychological research: Conceptual, strategic, and statistical considerations. Journal of Personality and Social Psychology, 51, 1173-1182.

Barth, J., Schneider, S., \& von Känel, R. (2010). Lack of social support in the etiology and the prognosis of coronary heart disease: A systematic review and meta-analysis. Psychosomatic Medicine, 72(3), 229-238.

Barth, J., Schumacher, M., \& Herrmann-Lingen, C. (2004). Depression as a risk factor for mortality in patients with coronary heart disease: A meta-analysis. Psychosomatic Medicine, 66(6), 802-813.

Bongard, S., \& Hodapp, V. (1997). Active coping, work-pace, and cardiovascular responses: Evidence from laboratory studies. Journal of Psychophysiology, 11(3), 227-237.

Booth-Kewley, S., \& Friedman, H. S. (1987). Psychological predictors of heart disease: A quantitative review. Psychological Bulletin, 101(3), 343-362.

Buceta, J. M., \& Bueno, A. M. (1996). Tratamiento psicológico después del infarto de miocardio. In J. M. Buceta \& A. M. Bueno (Eds.), Tratamiento psicológico de hábitos y enfermedades (pp. 455-493). Madrid: Pirámide.

Carneiro-Barrera, A., \& Rodríguez-Testal, J.F. (2017). Scale of Healthy Life Habits. Unpublished manuscript.

Cea, J. I., González, A., \& Brazal, J. J. (2002). Estrategias de afrontamiento e hipertensión arterial esencial. Revista Española de Motivación y Emoción, 4(7), 37-50.

Chida, Y., \& Steptoe, A. (2009). The association of anger and hostility with future coronary heart disease : A meta-analytic review of prospective evidence. Journal of the American College of Cardiology, 53(11), 936-946.

Coy, T. V. (1998). The effect of repressive coping style on cardiovascular reactivity and speech disturbances during stress. Dissertation Abstracts International: Section B. Sciences and Engineering, 58(8-B), 4512.

Coyne J. C., de Voogd J. N., (2012) Are we witnessing the decline effect in the Type D personality literature? What can be learned? Journal of Psychosomatic Research, 73, 401-407.

Denollet, J. (2005). DS14: Standard assessment of negative affectivity, social inhibition, and Type D personality. Psychosomatic Medicine, 67, 89-97.

Denollet, J., \& Brutsaert, D. L. (1998). Personality, disease severity, and the risk of long-term cardiac events in patients with decreased ejection fraction after myocardial infarction. Circulation, 97, 167-173.
Denollet, J., \& Pedersen, S. S. (2009). Anger, depression and anxiety in cardiac patients: The complexity of individual differences in psychological risk. Journal of the American College of Cardiology, 53, 947-949.

Denollet, J., \& Pedersen, S. S. (2012). Type D personality in patients with cardiovascular disorders. In R. Allan \& J. Fisher (Eds.), Heart and Mind: The practice of cardiac psychology (pp. 219-247). Washington, DC: American Psychological Association.

Denollet, J., Pedersen, S. S., Ong, A. T., Erdman, R. A., Serruys, P. W., \& van Domburg, R. T. (2006). Social inhibition modulates the effect of negative emotions on cardiac prognosis following percutaneous coronary intervention in the drug-eluting stent era. European Heart Journal, 27, 171-177.

Denollet, J., Sys, S. U., \& Brutsaert, D. L. (1995). Personality and mortality after myocardial infarction. Psychosomatic Medicine, 57, 582-591.

Denollet, J., Sys, S. U., Stroobant, N., Rombouts, H., Gillebert, T. C., \& Brutsaert, D. L. (1996). Personality as independent predictor of long-term mortality in patients with coronary heart disease. The Lancet, 347, 417-421.

Denollet, J., Tekle F. B., van der Voort, P. H., Alings, M., \& van den Broek, K. C. (2013). Age-related differences in the effect of psychological distress on mortality: Type D personality in younger versus older patients with cardiac arrhythmias. $B i$ oMed Research International, 2013, 246035.

Denollet, J., Vaes, J., \& Brutsaert, D. L. (2000). Inadequate response to treatment in coronary heart disease: Adverse effects of Type D personality and younger age on 5-year prognosis and quality of life. Circulation, 102, 630-635.

Fernández-Abascal, E. G., Martín, M. D., \& Domínguez, F. J. (2003). Factores de riesgo e intervenciones psicológicas eficaces en los trastornos cardiovasculares. Psichothema, 15, 615-630.

Gandek, B., Ware, J. E., Aaronson, N. K., Apolone, G., Bjorner, J. B., Brazier, J. E., ... Sullivan, M. (1998). Cross-validation of item selection and scoring for the SF-12 Health Survey in nine countries: Results from the IQOLA Project. International Quality of Life Assessment. Journal of Clinical Epidemiology, 51, 1171-1178.

García, M. A., \& Vallejo, G. (2011). Los efectos de terceras variables en la investigación psicológica. Anales de Psicología, 27(2), 550-561.

Goldberg, D. P., \& Hillier, V. F. (1979). A scaled version of the General Health Questionnaire. Psychological Medicine, 9, 139-145.

Grøntved, A., \& Hu, F. B. (2011). Television viewing and risk of type 2 diabetes, cardiovascular disease, and all-cause mortality: A meta-analysis. Journal of the American Medical Association, 305, 2448-2455.

Habra, M. E., Linden, W., Anderson, J. C., \& Weinberg, J. (2003). Type-D personality is related to cardiovascular and neuroendocrine reactivity to acute stress. Journal of Psychosomatic Research, 55, 235-245.

Hayes, A. F., \& Preacher, K. J. (2014). Statistical mediation analysis with a multicategorial independent variable. British Journal of Mathematical and Statistical Psychology, 67, 451-470.

Hirshkowitz, M., Whiton, K., Albert, S. M., Alessi, C., Bruni, O., DonCarlos, L., ... Ware, J. C. (2015). National Sleep Founda- 
tion's updated sleep duration recommendations: final report. Sleep Health, 1, 233-243.

Horwood, S., Anglim J., \& Tooley, G. (2016). Statistically modelling the relationships between Type D personality and social support, health behaviors and symptom severity in chronic illness groups. Psychology \& Health, 31(9), 1047-1063.

Kupper, N., Pedersen, S. S., Höfer, S., Saner, H., Oldridge, N., \& Denollet, J. (2013). Cross-cultural analysis of Type D (distressed) personality in 6222 patients with ischemic heart disease: A study from the International HeartQoL Project. International Journal of Cardiology, 166, 327-333.

Lobo, A., Pérez-Echevarría, M. J., \& Artal, J. (1986). Validity of the scaled General Health Questionnaire (GHQ-28) in a Spanish population. Psychological Medicine, 16, 135-140.

Molerio, O., \& García, G. (2004). Influencia del estrés y las emociones en la hipertensión arterial esencial. Revista Cubana Medicina, 43, 2-3.

Molloy, G. J., Perkins-Porras, L., Strike, P. C., \& Steptoe, A. (2008). Type D personality and cortisol in survivors of acute coronary syndrome. Psychosomatic Medicine, 70, 863-868.

Mommersteeg, P. M. C., Pot, I., Aarnoudse, W., Denollet, J., \& Widdershoven, J. W. (2013). Type D personality and patient-perceived health in nonsignificant coronary artery disease: The TWeesteden mIld STenosis (TWIST) study. Quality of Life Research 22(8), 2041-2050.

Montero, P., Bermúdez, J., \& Rueda, B. (2017). Adaptación al castellano de la Escala DS-14 («Type D Scale-14») para la medida de la personalidad tipo D. Revista de Psicopatología y Psicología Clínica, 22(1), 55-67.

Montero, P., Rueda, B., \& Bermúdez, J. (2012). Relación de la personalidad tipo D y el agotamiento vital con las emociones negativas y el ajuste psicológico a la enfermedad cardiaca. Revista de Psicopatología y Psicología Clínica, 17(2), 93-106.

Pedersen, S. S., \& Denollet, J. (2006). Is Type-D personality here to stay? Emerging evidence across cardiovascular patient groups. Current Cardiology Reviews, 2, 205-213.

Pluijmers, E. M., \& Denollet, J. (2017). Type D personality as a predictor of poor health outcomes in patients with cardiovascular disease. Netherlands Heart Journal, 25(4), 286-287.

Preacher, K. J., \& Hayes, A. F. (2008). Asymptotic and resampling strategies for assessing and comparing indirect effects in multiple mediator models. Behaviour Research Methods, 40, 879891.

Rodríguez-Testal, J.F. (2017). Escala Tipo D (Experimental adaptation). Unpublished document.
Roest, A. M., Martens, E. J., de Jonge, P., \& Denollet, J. (2010). Anxiety and risk of incident coronary heart disease: A meta-analysis. Journal of the American College of Cardiology, 56(1), 38-46.

Sociedad Española de Dietética y Ciencias de la Alimentación (2011). Recomendaciones nutricionales basadas en la evidencia para la prevención y el tratamiento del sobrepeso y la obesidad en adultos. Madrid: Acción Médica. Retrieved from http://www.nutricion.org

Sousa, V. D., \& Rojjanasrirat, W. (2011). Translation, adaptation and validation of instruments or scales for use in cross-cultural health care research: A clear and user-friendly guideline. Journal of Evaluation in Clinical Practice, 17(2), 268-274.

Svansdottir, E., Denollet, J., Thorsson, B., Gudnason, T., Halldorsdottir, S., Gudnason, V., ... Karlsson, H. D. (2013). Association of Type D personality with unhealthy lifestyle, and estimated risk of coronary events in the general Icelandic population. European Journal of Preventive Cardiology, 20, 322-330.

Unterrainer, J., Michal, M., Rahm, B., Hadzibegovic, J., Wild, P. S., Schulz, A., ... Beutel, M. E. (2016). Association of Type D personality with cognitive functioning in individuals with and without cardiovascular disease - The Gutenberg Health Study. International Journal of Cardiology, 214, 256-261.

Ware, J., Kosinski, M., \& Keller, S. (1996). A 12-item Short-Form health survey: Construction of scales and preliminary tests of reliability and validity. Medical Care, 34, 220-233.

Williams, L., Abbott, C., \& Kerr, R. (2015). Health behaviour mediates the relationship between Type D personality and subjective health in the general population. Journal of Health Psychology, 21, 2148-2155.

Williams, L., O'Carroll, R. E., \& O'Connor, R. C. (2009). Type-D personality and cardiac output in response to stress. Psychology and Health, 24, 489-500.

Williams, L., O'Connor, R. C., Howard, S., Hughes, B. M., Johnston, D. W., Hay, J. L., ... O'Carrol, R. E. (2008). Type-D personality mechanisms of effect: The role of health-related behavior and social support. Journal of Psychosomatic Research, 64, 63-69.

World Health Organization (2004). Global strategy on diet, physical activity and health. Retrieved from http://www.who.int/dietphysicalactivity/strategy/eb11344/strategy_english_web.pdf

World Health Organization Expert Consultation (2004). Appropriate body-mass index for Asian populations and its implications for policy and intervention strategies. Lancet, 363, 157163. 
Appendix

Recode table of the Healthy Lifestyle Habits questionnaire (HVS)

\begin{tabular}{|c|c|c|c|c|}
\hline HVS questions & Valor 3 & Valor 2 & Valor 1 & Valor 0 \\
\hline 1. Hours of watching TV per day & $0-2$ & 3 & 4 & $>4$ \\
\hline 2. Hours of sleeping per day & 8 & $7 ; 9$ & $6 ; 10$ & $5 ; 11$ \\
\hline 3. Consumption of fruits per day & 3,4 & 2 & 1 & 0 \\
\hline 4. Consumption of vegetables per day & $\geq 2$ & 1 & $1 / 2$ & 0 \\
\hline 5. Consumption of carbohydrates per day & 3 & $2 ; 4$ & $1 ; 5$ & $0 ; 6$ \\
\hline 6. Consumption of coffee or tea per day & 0 & 1 & 2 & $\geq 3$ \\
\hline 7. Consumption of cigarettes per day & 0 & $1-5$ & $6-10$ & $>10$ \\
\hline 8. Consumption of beer or wine per week & 0 & $1-7$ & $8-14$ & $>14$ \\
\hline 9. Consumption of spirit per week & 0 & 1 & $2-3$ & $\geq 4$ \\
\hline 10. Hours of physical activity per week & $2.5-7$ & $2 ; 8 ; 9$ & $1 ; 10$ & $0 ;>10$ \\
\hline 11. BMI & $18.5-24.99$ & $17-18.49 ; 25-29.99$ & $16-16.99 ; 30-39.99$ & $<16 ; \geq 40$ \\
\hline 12. Diastolic Blood Pressure & $0-7.5$ & $7.51-8.3$ & $8.31-9.4$ & $9.41-15$ \\
\hline 13. Systolic Blood Pressure & $10.80-12$ & $12.01-12.7$ & $12.71-14.2$ & $14.21-19$ \\
\hline
\end{tabular}

Note: HVS: Healthy lifestyle habits; BMI: Body-Mass Index. 